\title{
Myristic Acylation Site
}

National Cancer Institute

\section{Source}

National Cancer Institute. Myristic Acylation Site. NCI Thesaurus. Code C14052.

It refers to amino acid residue within a peptide that accepts covalent linkage of fatty acid, myristoyl group (C13H27-) as one of the co-translational modifications. N-

myristoylation, catalyzed by $\mathrm{N}$-myristoyltransferase, is the amide modification of proteins by the addition of a myristoyl group to an $\mathrm{N}$-terminal glycine residue. $(\mathrm{NCl})$ 